Document downloaded from:

http://hdl.handle.net/10251/59489

This paper must be cited as:

Periche Santamaría, A.; Heredia Gutiérrez, AB.; Escriche Roberto, MI.; Andrés Grau, AM.; Castelló Gómez, ML. (2015). Potential use of isomaltulose to produce healthier marshmallows. Food Science and Technology. 62(1):605-612. doi:10.1016/j.Iwt.2014.12.024.

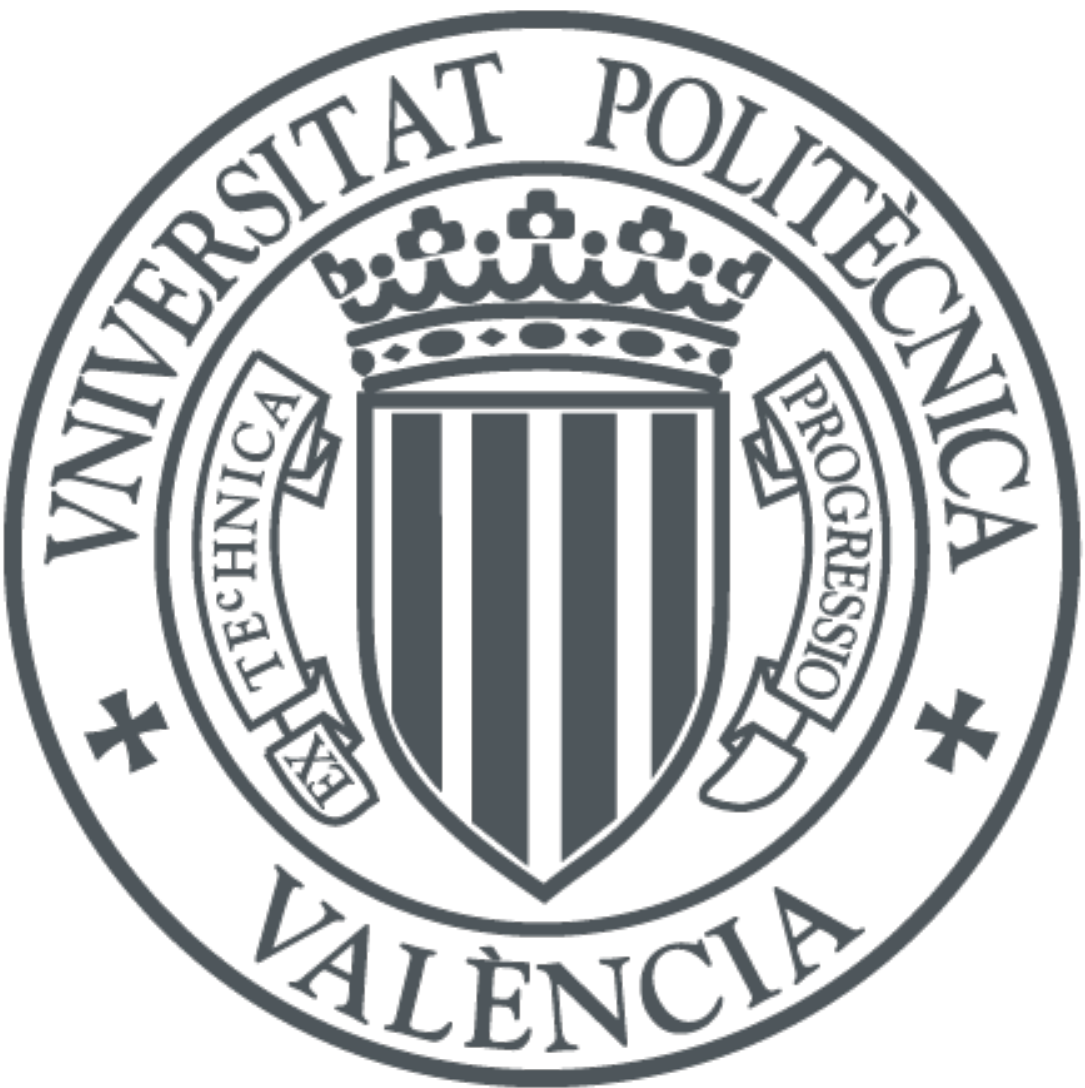

The final publication is available at

http://dx.doi.org/10.1016/j.Iwt.2014.12.024

Copyright Elsevier

Additional Information 


\title{
POTENTIAL USE OF ISOMALTULOSE TO PRODUCE HEALTHIER
}

\section{MARSHMALLOWS}

\author{
Periche, A., Heredia, A., Escriche, I., Andrés, A. Castelló, M.L.*
}

Universitat Politècnica de València

Institute of Food Engineering for Development. P.O.Box:46022 Valencia, Spain.

Corresponding author: mcasgo@upvnet.upv.es

Tel:+34963879967. Fax: +34963877956

\section{ABSTRACT}

Isomaltulose is a non-cariogenic sugar with a lower glycemic index but with the same caloric value and visual appearance as sucrose. Therefore, isomaltulose could potentially be used to produce healthier candies. In this regard, the aim of this research was to evaluate isomaltulose as a traditional sugar replacer in soft marshmallow type candies, in order to provide added value to these widely consumed products, making it possible to capture a new market niche. 18 formulations were studied combining different sugars (sucrose, glucose syrup, fructose and isomaltulose) and different percentages of gelatine (4,5 and 6). Analyses of composition ( ${ }^{\circ} \mathrm{Brix}$ and moisture content), $\mathrm{pH}$ and water activity $\left(\mathrm{a}_{\mathrm{w}}\right)$, instrumental colour and texture as well as a sensorial analysis were performed. Marshmallows with isomaltulose combined with fructose exhibited the lowest values of $\mathrm{pH}$ (4.99-5.14). Moreover, formulations with similar amount of isomaltulose and fructose presented lower instrumental hardness, higher cohesiveness and springiness, and the best sensory acceptance. A PLS multivariate analysis showed a good correlation between instrumental and sensorymechanical parameters. Therefore, instrumental measures of texture could be suitable for discerning an overall preference for marshmallows without using trained panellists. 
Keywords: marshmallows, isomaltulose, fructose, non-cariogenic, glycemic index and insulinemic index.

\section{INTRODUCTION}

Sweets are attractive due to their intense colours, shapes and characteristic aroma and taste, both for children and adults. Eating sweets in moderate amounts is pleasing and has a positive effect on well-being attributable to the sugar and flavourings present. However, these food products are not basic necessities and they are actually considered to be quite unhealthy since they are related to different diseases such as tooth decay, a sharp increase in the glycemic index and obesity. Despite these effects, they account for a significant volume of sales, candy consumption in Europe being valued at $€ 710,291,000$ in 2011 (Martínez, 2012).

The candy industry is a sector which is continually innovating in order to please consumers and develop new sugar free products meeting the demand for low calorie goods. The artificial sweeteners used as sugar substitutes show different disadvantages. For instance, polyalcohols have a laxative effect (Franz et al., 1994; Edwards, 2002) and intensive sweeteners such as aspartame have been related to the development of cancer and other health issues (AFSSA, 2002; Weihrauch and Diehl, 2004; Soffritti et al., 2007; Renwick and Nordmann, 2007). In confectionery products, it is usual to find the combination of different sugars such as sucrose, fructose, glucose with inverted sugar or glucose syrups which are meant to increase their solubility, decreasing the water activity of the final product and hence improving their stability. It is important to point out that gummy confectionery products have a particular structure, which is related to the combination of sugars with proteins,

51 resulting in the typical gel texture of jelly babies or others gums. Similarly, marshmallows have a foam-structure formed by the addition of air into the proteinsugar combination through hard stirring. Consequently, the structural role of sugarsubstitutes must be studied to assess whether the required mechanical properties of 
the traditional product are reached, or on the contrary, whether the end-products might be considered acceptable by consumers. An interesting natural sugar that can be used to revise the formula of candies is isomaltulose. It is a reducing disaccharide composed of glucose and fructose, just like sugar, but joined by a stronger glycoside bond type $\alpha-(1-6)$ (Weidenhangen \& Lorenz, 1957), which is why it cannot be attacked by bacteria responsible for tooth decay (Matsuyama et al., 1997). Therefore it is noncariogenic, and it is also slowly released in the bloodstream (Beneo-Palatinit, 2010; Bebyal, 2012; Bucke \& Cheetham, 1986). It is found in small amounts in honey and sugarcane juice (Bárez et al., 2000) but can be obtained massively from sucrose by means of an enzymatic process (Schiweck et al., 1990). It has only a third of the sweetening power of sucrose. It supplies the same amount of energy as table sugar but this energy lasts significantly longer. Furthermore, it has only a slight effect on sugar and insulin levels in human being and thus, it is totally digestible (Hawai et al., 1989; Lina et al., 2002).

Fructose is another natural sugar commonly found in fruits, which has been used for diabetics for many years because it has also a low glycemic index. However there is increasingly more controversy regarding the hazards of the fructose in high-fructose corn syrup (HFCS) when used in high amounts. There are some studies which conclude that high intakes of this syrup increase the risk of obesity since hepatic metabolism of fructose favours the novo lipogenesis (Bray et al., 2003; Elliot et al., 2002). Additionally, unlike glucose, fructose does not stimulate insulin secretion or enhance leptin production. Because insulin and leptin act as key afferent signals in the regulation of food intake and body weight, it could be suggested that dietary fructose contributes to an increased energy intake and weight gain. However, fructose could be safe if consumed in moderate quantities in healthy individuals.

80 In consideration of all the above, the aim of this study was to evaluate the use of

81 isomaltulose as a traditional sugar substitute in soft marshmallow type candies, in order 82 to obtain healthier products. Specifically, the influence of the formulation (type of sugar 
and level of gelatine) on compositional parameters, colour, texture and sensory acceptance of the marshmallows was analysed. In addition, a correlation between instrumental and sensory variables was performed.

\section{MATERIALS AND METHODS}

\subsection{Materials}

The ingredients used in the formulation of marshmallows were: sucrose (Azucarera Ebro S.L., Burgos, Spain), fructose (Gabot Biochemical Industries, Haifa, Israel), isomaltulose (Beneo-Palatinit, Mannheim, Germany), glucose syrup 43 DE (Emilio Peña, S.A., Valencia, Spain), gelatine A 220 Bloom (Juncà Gelatines S.L., Girona, Spain), corn starch (Roquette Laisa S.A., Valencia, Spain), natural red liquid colour (Roha Europe S.L.U., Valencia, Spain), strawberry flavouring (Flavorix Aromáticos S.A., Madrid, Spain) and sunflower oil (Koipesol, Jaén, Spain).

\subsection{Experimental Methodology}

The marshmallows were confected with $36 \mathrm{~g}$ of water/100 g, 58-60 g of sugars $/ 100 \mathrm{~g}$ and 4-6 $\mathrm{g}$ of gelatine/100 $\mathrm{g}$. The percentage of sugars depended on the amount of gelatine used. Furthermore, $0.5 \mathrm{mg} / \mathrm{kg}$ of strawberry flavouring and $0.2 \mathrm{mg} / \mathrm{kg}$ of red colouring were added. Six different mixtures of sugars were studied. In the case of the control samples, the total sugar content was composed of 40 and $60 \mathrm{~g}$ of sucrose and glucose syrup per $100 \mathrm{~g}$ of total sugars respectively, and the code was (S). The new samples were obtained by replacing the sugars with different combinations of isomaltulose, glucose syrup or fructose. In order to simplify the description of each sample, the percentage of the total amount of sugars replaced is shown between brackets along with the code used: isomaltulose:glucose syrup (l: $40 \mathrm{~g}$ of isomaltulose and $60 \mathrm{~g}$ of glucose syrup per $100 \mathrm{~g}$ of total sugars), fructose:glucose syrup (F: $40 \mathrm{~g}$ of 
111 fructose and $60 \mathrm{~g}$ of glucose syrup per $100 \mathrm{~g}$ of total sugars), isomaltulose:fructose

112 (I30: $30 \mathrm{~g}$ of isomaltulose and $70 \mathrm{~g}$ of fructose per $100 \mathrm{~g}$ of total sugars),

113 isomaltulose:fructose (150: $50 \mathrm{~g}$ of isomaltulose and $50 \mathrm{~g}$ of fructose per $100 \mathrm{~g}$ of total

114 sugars), isomaltulose:fructose (170: $70 \mathrm{~g}$ of isomaltulose and $30 \mathrm{~g}$ of fructose per $100 \mathrm{~g}$

115 of total sugars). Besides, the level of gelatin $(4,5$ or $6 \mathrm{~g} / 100 \mathrm{~g})$ was subsequently noted

116 by including the percentage of gelatine used (S4, S5, S6, 14, I5, I6, etc.) after the code,

117 a total of 17 different formulations being studied plus the control. Commercial

118 marshmallows were also analysed to compare them to the new ones only in terms of

119 composition, water activity and mechanical properties, but not colour since they did not

120 have similar optical properties.

121 Each formulation was made in a thermal blender (Thermomix, TM31, Vorwerk,

122 Wuppertal, Germany) by blending the sugars and water until they reached boiling

123 temperature at $300 \mathrm{rpm}$ for 10 minutes. This mixture was shaken until reaching $60^{\circ} \mathrm{C}$

124 and $\mathrm{pH}$ and ${ }^{\circ}$ Brix were measured. The gelatine was then dissolved in water in a ratio of

$1251 \mathrm{~g}$ of gelatine per $2 \mathrm{~g}$ of water to obtain a homogeneous mix and subsequently added

126 to the syrup with the flavouring and colouring agents. All the ingredients were blended

127 for 5 minutes at $60^{\circ} \mathrm{C}$ and $6.04 \mathrm{G}$-force. Then, the syrup was shaken for 10 minutes at

$128231.82 \mathrm{G}$-force to add air to the mixture, which is what mainly accounts for the texture

129 of the marshmallows. For molding purposes, the final mixture was poured into silicone

130 molds with a thin layer of sunflower oil. Finally, the molds were placed in a chamber at

$13120^{\circ} \mathrm{C}$ for 24 hours. The samples were then removed from their mould and covered with

132 starch to prevent the samples from sticking together. After an additional 24 hours,

133 analyses of texture, colour, water activity and moisture performed. Each formulation

134 was performed by triplicate. 
139 Moisture content and water activity analyses were carried out on the final products.

140 Moisture content was determined gravimetrically by drying to a constant weight in a 141 vacuum oven at $60{ }^{\circ} \mathrm{C}$ (method 20.103 AOAC, 2000). Water activity $\left(\mathrm{a}_{\mathrm{w}}\right)$ was 142 determined with a dew point hygrometer (FA-st lab, GBX, Valence, France). Soluble 143 solid content ( ${ }^{\circ} \mathrm{Brix}$ ) was measured with a refractometer at $20^{\circ} \mathrm{C}$ (ATAGO $3 \mathrm{~T}$, Tokyo, 144 Japan) and $\mathrm{pH}$ was determined with a $\mathrm{pH}$-meter (SevenEasy, Mettler Toledo, 145 Greifensee, Switzerland) in the initial syrup. All measurements were carried out in 146 triplicate.

\subsubsection{Colour}

149 Instrumental measurements of colour were conducted at room temperature in a

150 Konica-Minolta spectrophotometer (model CM-3600d, Singapore, Republic of 151 Singapore) by placing the marshmallow on the diaphragm aperture $(8 \mathrm{~mm})$. CIEL*a* ${ }^{*}$ 152 coordinates were obtained using illuminant D65 and standard observer $\left(10^{\circ}\right.$ visual 153 field) as references. Registered parameters were: L* (brightness), $a^{*}$ (red component), $154 b^{*}$ (yellow component), chroma $\left(C^{*}=\left(a^{* 2}+b^{* 2}\right)^{1 / 2}\right)$ and hue $\left(h^{*}=\operatorname{arctg}\left(b^{*} / a^{*}\right)\right)$.

\subsubsection{Texture}

156 The samples were examined with Texture Profile Analysis test (TPA) using a TA.XT 157 plus Texture Analyzer (Stable Micro Systems, Godalming, U.K.). Instruments were 158 equipped with a load cell of $50 \mathrm{~kg}$ and a $45 \mathrm{~mm}$ diameter cylindrical probe. The test 159 conditions involved two consecutive cycles of $50 \%$ compression with $15 \mathrm{~s}$ between 160 cycles. The test speed was $1 \mathrm{~mm} / \mathrm{s}$. From the resulting force-time curve the following 161 parameters were quantified, and are defined by Bourne (1978) as: hardness (N) 162 (maximum peak force during the first compression cycle), springiness (the height that 163 the sample recovers during the time that elapses between the end of the first cycle and 164 the beginning of the second cycle), cohesiveness (the ratio of the positive force area 
165 during the second compression and the first compression), gumminess $(N)$ (hardness $x$

166 cohesiveness).

\subsubsection{Sensory Evaluation}

168 An acceptance test using a 9-point hedonic scale (ISO 4121:2003, Jiménez et al. 2013)

169 was used to evaluate the following attributes: appearance, colour, strawberry flavour,

170 sweetness, texture, hardness, gumminess, springiness, cohesiveness, global

171 preference and intention of buying (ISO 5492:2008). The panel consisted of 20 trained

172 panellists (13 women and 7 males aged from 25 to 45 ) who are regular consumers of

173 this kind of sweet. The sensory analysis took place in 2 sessions on separate days.

174 The panellists evaluated 3 formulations $(S 4,1504,1505)$ on the first day and 2

175 formulations (I506 and S4-Ar [control which had double the added aroma]) on second

176 day; each of the different formulations ( 3 units) was presented independently. Testing

177 was conducted in a sensory evaluation laboratory built according to the international

178 standards for test rooms.

$180 \quad 2.4$ Statistical Analyses

181 Statgraphics Centurion was used to perform the statistical analyses. Analyses of 182 variance (multifactor ANOVA) were carried out to discern whether the effect of the 183 process variables (kind of sugar and percentage of gelatine) on the final product was 184 significant. The interactions between factors were considered. Furthermore, Principal 185 Component Analysis (PCA) and Partial Least Square regression (PLS2) were applied 186 to describe the relationships between the sensory and the instrumental texture 187 measurements. These analyses were performed using the Unscrambler version.10X 188 (CAMO Process AS, Oslo, Norway).

\section{RESULTS AND DISCUSSION}


192 Table 1 shows the resulting ${ }^{\circ}$ Brix and $\mathrm{pH}$ of syrup for each formulation in addition to

193 moisture content (g of water/100 g), water activity and the sweetness of the

194 marshmallows. As can be observed, samples confected with isomaltulose and glucose

195 syrup had the lowest content of soluble solids, which could mean that these products

196 will have a shorter shelf life in comparison with the control sample. However,

197 marshmallows prepared with different proportions of isomaltulose and fructose in

198 granulated form showed values of ${ }^{\circ}$ Brix which were very similar to those of the control

199 samples.

200 It is noteworthy that the use of glucose syrup in the preparation of marshmallows led to

201 greater values of $\mathrm{pH}$ in the syrup, in comparison to samples prepared directly with

202 mixture of sugars in granulated form. These results could affect the shelf-life of the final

203 product since fructose and other reducing sugars are affected by $\mathrm{pH}$ differently. They

204 are stable in modestly acidic environments but become unstable as the $\mathrm{pH}$ approaches

205 neutral, and enters the alkaline range. As the $\mathrm{pH}$ of the system rises, the sugars

206 become more chemically active and reactive, breaking down into colour bodies and

207 flavour compounds, and reacting with proteins. This $\mathrm{pH}$ instability is marked by

208 accelerated colour degradation, going from colourless to yellow to brown (Helstad,

209 2006). In this respect, given the decrease by almost two points of $\mathrm{pH}$ in samples

210 confected with isomaltulose-fructose as compared to the $\mathrm{pH}$ in other cases, these

211 products might have an increased shelf life.

212 On the whole, values of moisture content were in the recommended range for this kind

213 of products (15-22 $\mathrm{g}$ of water/100g) (Edwards, 2002). In the case of commercial

214 marshmallows, moisture content was $14.784(0.110) \mathrm{g}$ of water/100g. Moreover, the

215 statistical analysis evidences the significant effect of the interaction between the

216 formulation used and the percentage of gelatine considered. More specifically, each

217 formulation behaved differently depending on the percentage of gelatine used. Thus,

218 control samples (60 $\mathrm{g}$ of glucose syrup and $40 \mathrm{~g}$ of sucrose per $100 \mathrm{~g}$ of total content of

219 sugars) showed the lowest values of moisture content since the percentage of gelatine 
220 increased in proportion to the value of soluble solids observed in the syrup. In contrast, 221 samples with $60 \mathrm{~g}$ of glucose syrup and $40 \mathrm{~g}$ of isomaltulose per $100 \mathrm{~g}$ of total content

222 of sugars, showed the highest values of moisture content when $4 \mathrm{~g}$ of gelatine/100 $\mathrm{g}$ 223 was used. In samples where other levels of gelatine were used the behaviour was 224 opposite that of the control samples. On the other hand, samples confected with 225 isomaltulose-fructose mixtures had the highest moisture values, which were similar to 226 the values recorded for control samples with 4 and $5 \mathrm{~g}$ of gelatine $/ 100 \mathrm{~g}$. Only samples $227 \mathrm{I} 170$ with 4 and $5 \mathrm{~g}$ of gelatine/100 $\mathrm{g}$ and control samples with $6 \mathrm{~g}$ of gelatine/100 $\mathrm{g}$ 228 reached lower values of humidity than in the case of commercial marshmallows. Based on these results, it can be concluded that the replacement of sucrose by fructose and especially by isomaltulose in samples with glucose syrup led to an increase in the

231 moisture content of the final product to levels even higher than the recommendable 232 values when low percentages of gelatine were used. However, the combination of 233 fructose-isomaltulose generally decreased the percentage of water in samples 234 regardless of the amount of gelatine used.

235 In terms of water activity, control samples and marshmallows prepared with 236 isomaltulose and glucose syrup, and with only the lowest level of gelatine, showed the 237 highest water activity, meaning that there was more water susceptible to microbiology 238 spoilage reactions and consequently potential health risks. Moreover, it is noteworthy 239 that among the samples prepared with syrup, those containing isomaltulose showed 240 the greatest water activity, especially for the lowest level of gelatine. In the case of 241 isomaltulose-fructose samples, water activity of I30 was the closest to the water activity 242 in commercial marshmallows (0.6516), the amount of gelatine used having no effect on 243 this value. Besides, water activity rose in proportion to the percentage of isomaltulose.

244 With respect to the influence of gelatine, higher water activity was only observed in 245 samples 170 with $4 \mathrm{~g}$ of gelatine/100 $\mathrm{g}$.

246 In line with the inherent sweetness of the sugars studied, the higher the proportion of 247 isomaltulose the lower the sweetness of the samples. 
248 To sum up, mixtures of isomaltulose-fructose would be able to reach values of moisture

249 content, soluble solids and water activity similar to the commercial ones. Furthermore,

$250 \mathrm{pH}$ was lower than in control samples which could improve their stability.

\subsection{Instrumental mechanical and optical properties}

253 Figure 1 shows the instrumental TPA attributes (springiness, hardness, cohesiveness

254 and gumminess) of the marshmallows obtained using the different formulations.

255 Results indicated springiness values for all samples which were higher than 0.9, similar

256 to the values shown for the control samples, regardless of the type of sugar and the

257 percentage of gelatine in their formulation. The inclusion of gelatine in the formulation

258 provided a visco-elastic texture and stable foam that led to the high springiness

259 desirable for this kind of products (PB Gelatines, 2012; Hamann et al.; 2006). With

260 respect to hardness, the higher the percentage of gelatine, the higher the hardness of

261 the samples, except for marshmallows confected with the maximum quantity of

262 isomaltulose (170). The effect of gelatine on hardness also depended on the blend of

263 sugars used (figure 1), this interaction being more notable in samples confected with

264 the syrup of glucose (S, F and I). The samples confected with the same type of sugars

265 as those used in the control had a higher hardness than that of the other formulations

266 for a given percentage of gelatine, with the exception of samples with the maximum

267 percentage of isomaltulose (170). The highest value of hardness observed in the

268 samples 170 with 4 and $5 \mathrm{~g}$ of gelatine/100 g, could be related to the crystallization of

269 isomaltulose during the cooling step due to the low solubility of this sugar at room

270 temperature (Mitchell, 2006). An increase in the level of jellification to $6 \mathrm{~g}$ of

271 gelatine/100 g seemed to limit this phenomenon (PB Gelatins, 2012; Pérez, 2004). This

272 result was also the consequence of the low structural cohesiveness exhibited by these

273 samples (figure 1) which allows isomaltulose molecules to achieve enough mobility to

274 form crystals. In turn, the intermolecular interaction or cohesiveness of any of the 
samples I, F, I30 and I50, and therefore their structural integrity, was higher than in

276 control samples (S).

277 Finally, gumminess, which comes from the interaction between the hardness and the cohesive forces taking place at structural level, was close to 1 in all samples.

Table 2 shows the values of luminosity and coordinates $a^{*}$ and $b^{*}$, and the chrome and hue of marshmallows depending on the type of sugar and the percentage of gelatine.

281 Table 3 shows the values of the F-ratio for each mechanical and optical parameter 282 obtained in the ANOVA according to the factor studied (formulation and percentage of 283 gelatine) and their interaction.

284 As can be observed, in all cases the percentage of gelatine was the factor with the greatest influence on luminosity and $a^{*}$ and $b^{*}$ coordinates. Specifically, the lower the level of gelatine the lower the luminosity, especially in samples obtained with glucose syrup-fructose and with glucose syrup-isomaltulose. In control samples, this increase was observed only in the leap between 4 and $5 \mathrm{~g}$ of gelatine/100 g, samples with 5 and $6 \mathrm{~g}$ of gelatine $/ 100 \mathrm{~g}$ having similar values of $\mathrm{L}^{*}$. In this regard, the use of $5 \mathrm{~g}$ of gelatine/100 $\mathrm{g}$ would be enough to obtain luminosity very close to in the case of the control samples. Besides, for this particular level of gelatine, values of luminosity were very similar in all the formulations considered.

293 With regard to coordinate $a^{*}$, the percentage of gelatine again had a greater significant

294 effect than the formulation used or their interaction. Except for in the case of the control samples, marshmallows with $4 \mathrm{~g}$ of gelatine/100 $\mathrm{g}$, showed the highest values of coordinate $\mathrm{a}^{*}$, especially in formulation $\mathrm{F}$ and $\mathrm{I}$. This behaviour would indicate that samples with a lower content of gelatine would tend to have reddish colours. Nevertheless, in samples with 5 and $6 \mathrm{~g}$ of gelatine/100 $\mathrm{g}$, there was no defined

299 tendency with respect to the values of coordinate $a^{*}$ as in the case of luminosity.

300 In coordinate $b^{*}$, differences arising due to the percentage of gelatine were less evident 301 than in $L^{*}$ and $a^{*}$. A significant decrease of coordinate $b^{*}$ was only observed in samples $302 \mathrm{I} 30,170$ and especially in I, when $4 \mathrm{~g}$ of gelatine/100 $\mathrm{g}$ was used. On this occasion, the 
303 formulation and percentage of gelatine had a similar effect. In any case, the values of

304 the $b^{*}$ coordinate were very low so the differences found would not lead to important

305 deviations in colour when they are placed in the chromatic diagram $b^{*} a^{*}$.

306 In accordance with the previous results, chrome values showed a tendency which was

307 similar to that of the values of coordinate $a^{*}$ due to its higher numerical value in 308 comparison with coordinate $\mathrm{b}^{*}$. With the exception of samples I, hue was kept at an

309 average angle of approximately $8^{\circ}$. Samples I were in the fourth quadrant of the

310 chromatic diagram $b^{*} a^{*}$, with an angle of $350^{\circ}$ which was very close to the other

311 samples.

312 In general, the colour of the samples prepared with glucose syrup-isomaltulose differed

313 most from the colour of the control samples. However, the differences in colour were

314 minimal, not being visually perceptible. On the other hand, it would be advisable to use

315 a percentage of gelatine of between 4 and $5 \mathrm{~g}$ of gelatine/100 $\mathrm{g}$ because despite the

316 fact that were changes when $4 \mathrm{~g}$ of gelatine/100 $\mathrm{g}$ was used, they were almost

317 unnoticeable, and no improvements were observed when using the highest percentage

318 of gelatine, which would also lead to a higher cost.

\subsection{Sensory Evaluation}

321 As was described previously, the instrumental texture measurements were made for

322 the 18 possible marshmallows formulations (6 combinations of sugars and 3 levels of 323 gelatine). However, due to the complexity of the sensory studies, only a few of these

324 formulations were selected. To this end, the information given by a principal component analysis (PCA) of the instrumental parameters (hardness, gumminess, cohesiveness and elasticity) obtained from the 18 formulations as well as a commercial sample (C),

327 was taken into account. The latter was also included to facilitate selection of the

328 formulations. The first two components of this PCA explained $83 \%$ of the total variance

329 (PC1, $63 \%$ and PC2, $20 \%$ ). The formulations were selected due to their proximity to

330 the commercial sample, which means they had a similar texture profile. S4 (with $4 \mathrm{~g}$ of 
331 gelatine $/ 100 \mathrm{~g}$ ) was selected from those exclusively made with sucrose (sugar used in

332 commercial sweets). The differences between the formulations made with a mixture of 333 isomaltulose and fructose, with a 30:70 ratio of these sugars and a 50:50 ratio, were 334 practically non-existent. Therefore, samples which had the highest levels of 335 isomaltulose $(1504,1505,1506)$ were chosen because of the advantages of this sugar to 336 consumer health.

337 The result of the ANOVA (using "formulation" as a factor), carried out for the different 338 attributes evaluated by the panellists, is shown in a radial chart (figure 2). This figure 339 shows the average score for each attribute evaluated by the panellists, and the F-ratio 340 of each attribute in brackets. There are no significant differences between the samples 341 evaluated by the panellists for any of the attributes. However, considering the average 342 values, some differences between the samples can be seen. Sample S4 scored lowest 343 on all the attributes except hardness. This low score was reflected in global 344 appreciation and intention of buying.

345 In relation to global appearance and colour, sample 1505 was the most appreciated. 346 Regarding texture attributes (hardness, gumminess, cohesiveness, springiness), 347 samples 1504 and 1506 had similar scores; on the contrary, sample 1505 obtained 348 slightly lower scores. As regards the aroma attribute, sample S4-Ar was the best. As 349 this formulation had double the added aroma, it is clear that the panellists liked a more 350 intense aroma in this kind of product. Finally, sample 1504 had the best score for global 351 preference and intention of buying.

352 In order to ascertain the possible linear dependence between the sensory attributes, 353 and especially to know which attribute has more influence on global preference and 354 intention of buying, Pearson correlation coefficients (95.0\% confidence level) were 355 calculated for each pair of variables. Table 4 shows the correlation matrix obtained.

356 The best positive correlations were shown for intention of buying-global preference 357 (0.959) and for intention of buying-texture (0.942). Moreover, a positive correlation 358 between colour-overall appearance (0.908) and cohesiveness-gumminess (0.878) 
were found. Therefore, it is texture that defines acceptability and intention of buying the

360 product.

361 A PCA analysis was conducted to better understand the relationship between the samples and the evaluated attributes from a descriptive point of view. Figure 3 shows the biplot of the sample scores and the attribute loadings obtained by means of this analysis. The first two dimensions explained $77 \%$ of the total variance (PC1, 50\% and PC2, 27\%). Samples with isomaltulose $(1504,1505,1506)$ are placed at the right side next to the highest values of the sensory variables analysed and hence the most preferred, especially for 1504 (with $4 \mathrm{~g}$ of gelatine/100 g). On the other hand S4 and S4Ar are situated on the opposite side, which implies the lowest values of these variables for these two last samples, especially for S4.

\subsection{Correlation between sensory and instrumental variables}

372 As explained before, texture is the characteristic that decisively influences the

373 consumer when buying this type of product. For this reason, it was decided to assess

374 whether texture sensory variables, as well as global preference, are correlated with the instrumental variables. With this aim, figure 4 shows the results from PLS2 regression analysis, which describes the relationship between the instrumental variables (Xmatrix) and the acceptability score for the sensory attributes (Y-matrix). The sensory

378 parameters placed in the outer ellipse are correlated with the instrumental variables, with the exception of sensorial hardness, which being placed in the inner ellipse is not correlated $\left(r^{2}=50 \%\right)$. In summary, it could be asserted that the instrumental texture analyses are suitable and can be used to discern the overall preference for marshmallows without using trained panellists.

\section{CONCLUSIONS}


385 According to the mechanical properties, the total sugar content of marshmallows could 386 be replaced by a mixture of isomaltulose and fructose in a 1:1 ratio. Marshmallows 387 prepared under these conditions obtained a better sensory evaluation than those 388 confected with sucrose and glucose syrup. Therefore, isomaltulose could be a good 389 substitute for traditional sugars in marshmallows. Additionally, a good correlation was

390 found between the instrumental parameters and the acceptance sensory attributes, 391 and global preference, indicating that texture measurements can be used for quality 392 assessment purposes. To sum up, isomaltulose could be considered by the 393 confectionary industry to obtain healthier candies.

\section{ACKNOWLEDGMENTS}

397 The authors thank the Universitat Politècnica de València for funding the project PAID 2011-ref: 2012 and the PhD scholarship.

\section{REFERENCES}

401

402

403

404

405

406

407

408

410

AFSSA. (2002). Rapport de l’Agence Française de Sécurité Sanitaire des Aliments sur la question d'un éventuel lien entre exposition à l'aspartame et tumeurs du cerveau. Maisons-Alfort, France.

AOAC (2000). Official Methods of Analyisis of AOAC International (17th edition). Gaithersburg, MD, USA.

Badet C\& Richard B (2004). Étude clinique de la carie. EMC-Dentisterie, 1,40-48.

Barez J, Villanova R, Garcia S, Pala T, Paramas A, \& Sanchez J (2000) Geographical discrimination of honeys through the employment of sugar patterns and common chemical quality parameters. European Food Research and Technology, 210, 437-444.

Bebyal (2012). Byaltulosa. Available at: http://bebyal.com.mx/Edulcorantes/Byaltulosa.pdf. Accessed 22 Juny 2012. 
411 Beneo-palatinit (2010). Palatinose ${ }^{\mathrm{TM}}$. The only toothfriendly sugar for optimized energy supply.

$412 \quad$ Available at: www.beneopalatinit.com. Accessed 25 Juny 2012.

413 Bourne MC (1978). Texture profile analysis. Food technology, 32, 62-66.

414 Bray GA, Nielsen SJ \& Popkin BM (2004). Consumption of high-fructose corn syrup in beverages may 415 play a role in the epidemic of obesity. American Society for Clinical Nutrition, 79 (4), 537-543.

$416 *$ Bucke C \& Cheetham PS (1986). Method of reducing dental plaque formation with products for human 417 or animal consumption using isomaltulose sucrose substitute. United States of America Patent No 4,587,119.

*Edwards WP (2002). La ciencia de las golosinas. Editorial Acribia, S.A., Zaragoza.

Elliot SS, Keim NL, Stern JS, Teff K \& Havel PJ (2002). Fructose, weight gain, and the insulin resistance syndrome. The American Journal of Clinical Nutrition, 76(5),911-922.

Franz MJ, Horton ES, Bantle JP, Beebe CA, Brunzell JD, Coulston AM, Henry RR, Hoogwerf BJ \& Stacpool PW (1994). Nutrition Principles for the Management of Daibetes and Related Complications. Technical Review. Diabetes Care, 17(5), 490-518.

González P, Camacho F \& Robles A (1989). Hidrolizados enzimáticos de interés en la industria agroalimentaria. I. Hidrolizados de cereales. Alimentación, equipos y tecnología, 8(3), 201-207.

Hamann DD, Zhang J, Daubert CR, Foegeding EA \& Diehl KC (2006). Analysis of compression, tension and torsion for testing food gel fracture properties. Journal of Texture Studies, 37(6), 620-639.

*Hawai K, Yoshikawa H, Murayam Y, Okuda Y \& Yamashita K (1989). Usefulness of palatinose as a caloric sweetener for diabetic patients. Hormone and Metabolic Research, 21, 338-340.

Helstad S (2006) Ingredients interactions: Sweeteners. In: McPherson A and Gaonkar AG (ed) Ingredient interactions: Effects on Food Quality. Taylor \& Francis. New York, pp.167-194.

ISO 5492 (2008). Sensory analysis. Vocabulary. International Organization for Standardization.

ISO 4121 (2003). Sensory analysis. Guidelines for the use of quantitative response scales. International

*Jiménez-Colmenero F, Triki M, Herrero AM, Rodríguez-Salas L \& Ruiz-Capillas C (2013). Healthy oil combination stabilized in a konjac matrix as pork fat replacement in low-fat, PUFA-enriched, dry fermented sausages. LWT - Food Science and Technology, 51, 158-163. toxicologycal studies. Food and Chemical Toxicology, 40, 1375-1381. 
441

442

443

444

445

446

447

448

449

450

451

452

453

454

455

456

457

458

459

460

461

462

463

464

465

466

467

468

469

470

Matsuyama J, Sato T \& Hoshino E (1997). Acid production from palatinose, palatinit, erythritol and maltitol by bacteria isolated from dental plaque on human deciduous teeth. Japanese Association for Oral Biology, 39, 91-99.

Mitchell HL (2006). Sweeteners and Sugar Alternatives in Food Technology. Editorial Blackwell Publishing Ltd, Oxford, UK.

PB Gelatins. (2012). Propiedades estabilizantes del batido y la espuma. Available at: www.pbgelatins.com/es/applications/food-applications/confectionary. Accessed 27 juny 2012.

Pérez P (2004). Evaluación de la Calidad y Funcionalidad de la goma de Mascar. PhD Thesis. Departamento de Ciencias de Alimentos. Universidad de las Américas Puebla, México.

Martínez O (2012). Report Spanish Confectionary Association. Produlce. Madrid, Spain.

Renwick AG \& Nordmann H (2007). First European conference on aspartame: Putting safety and benefits into perspective. Synopsis of presentations and conclusions: Food and Chemical Toxicology, 45 (7), 1308-1313.

Schiweck H, Munir M, Rapp K, Schenider B \& Bogel M (1990). New developments in the use of sucrose as an industrial bulk chemical. Zuckerindustrie, 115, 555-565.

Soffritti M, Belpoggi F, Tibaldi E, Esposti DD \& Lauriola M (2007). Life-Span Exposure to Low Doses of Aspartame Beginning during Prenatal Life Increases Cancer Effects in Rats. Environmental Health Perspectives.115(9), 1293-1297.

Torres N, Palacios B, Noriega L, Tovar AR (2006). Índice glicémico, índice insulinémico y carga glicémica de bebidas de soya con un contenido bajo y alto en hidratos de carbono. Revista de investigación clínica, 58(5), 487-497.

Weidenhagen R \& Lorenz S (1957). Palatinose (6-alpha-glucopyr- 716 anosido-fructofuranose), ein neues bakterielles Umwandlungsprodukt der Saccharose. Zeitschrift fur die Zuckerindustrie, 7, 533534; und Angewandte Chemie, 69, 641.

Weihrauch MR \& Diehl V (2004). Artificial sweeteners--do they bear a carcinogenic risk? Annals of Oncology, 15(10), 1460-1465. 
472 Table 1. Mean and standard deviation of ${ }^{\circ} \mathrm{Brix}$ and $\mathrm{pH}$ of the initial syrup and moisture content,

473 water activity and sweetness of the marshmallows $(n=3)$

474

\begin{tabular}{|c|c|c|c|c|c|c|}
\hline \multirow[b]{2}{*}{ Formulation } & \multirow[b]{2}{*}{$\begin{array}{l}\% \\
\text { Gelatin }\end{array}$} & \multicolumn{2}{|c|}{ Initial syrup } & \multicolumn{2}{|l|}{ Product: marshmallow } & \multirow[b]{2}{*}{ Sweetness.* } \\
\hline & & $\stackrel{\circ}{\circ}$ rix & $\mathrm{pH}$ & Moisture content (g/100g) & $a_{w}$ & \\
\hline \multirow{3}{*}{$\mathbf{S}$} & 4 & & & $18.8(0.3)^{\mathrm{ad}}$ & $0.816(0.002)^{\mathrm{b}}$ & 0.42 \\
\hline & 5 & $75.4(1.3)^{\mathrm{a}}$ & $6.57(0.09)^{a}$ & $16.0(1.4)^{\mathrm{b}}$ & $0.736(0.003)^{c}$ & 0.41 \\
\hline & 6 & & & $12.8(0.8)^{\mathrm{c}}$ & $0.687(0.005)^{\mathrm{d}}$ & 0.41 \\
\hline \multirow{3}{*}{$\mathbf{F}$} & 4 & & & $20.8(0.3)^{\mathrm{ad}}$ & $0.797(0.005)^{\mathrm{b}}$ & 0.54 \\
\hline & 5 & $71(4)^{b}$ & $6.68(0.18)^{\mathrm{a}}$ & $19.1(0.5)^{\mathrm{ad}}$ & $0.721(0.002)^{c}$ & 0.53 \\
\hline & 6 & & & $18.1(0.8)^{\mathrm{ab}}$ & $0.739(0.003)^{c}$ & 0.52 \\
\hline \multirow{3}{*}{ I } & 4 & & & $23.9(1.9)^{\mathrm{e}}$ & $0.873(0.004)^{\mathrm{a}}$ & 0.25 \\
\hline & 5 & $65.0(0.6)^{c}$ & $6.69(0.13)^{\mathrm{a}}$ & $19.0(0.5)^{\mathrm{ad}}$ & $0.785(0.004)^{b}$ & 0.25 \\
\hline & 6 & & & $22(5)^{\mathrm{de}}$ & $0.786(0.005)^{b}$ & 0.25 \\
\hline \multirow{3}{*}{ I30 } & 4 & & & $17.2(1.3)^{\mathrm{ab}}$ & $0.683(0.002)^{\mathrm{d}}$ & 0.68 \\
\hline & 5 & $72.9(0.4)^{\mathrm{d}}$ & $5.13(0.09)^{\mathrm{b}}$ & $17.31(1.06)^{\mathrm{ab}}$ & $0.653(0.004)^{\mathrm{d}}$ & 0.67 \\
\hline & 6 & & & $18.4(1.7)^{\mathrm{ad}}$ & $0.671(0.007)^{\mathrm{d}}$ & 0.66 \\
\hline \multirow{3}{*}{ I50 } & 4 & & & $16.2(0.8)^{b}$ & $0.715(0.006)^{c}$ & 0.54 \\
\hline & 5 & $73.7(1.2)^{\mathrm{d}}$ & $5.14(0.15)^{\mathrm{b}}$ & $18.32(0.97)^{\mathrm{abd}}$ & $0.716(0.004)^{c}$ & 0.53 \\
\hline & 6 & & & $17.27(1.15)^{\mathrm{ab}}$ & $0.678(0.003)^{\mathrm{d}}$ & 0.52 \\
\hline \multirow{3}{*}{ I70 } & 4 & & & $13.9(1.9)^{\mathrm{bc}}$ & $0.762(0.003)^{\mathrm{b}}$ & 0.40 \\
\hline & 5 & $73.4(1.2)^{\mathrm{d}}$ & $4.992(0.108)^{c}$ & $14.0(0.7)^{\mathrm{bc}}$ & $0.679(0.002)^{\mathrm{d}}$ & 0.39 \\
\hline & 6 & & & $17.5(1.3)^{\mathrm{ab}}$ & $0.709(0.004)^{c}$ & 0.38 \\
\hline
\end{tabular}

475 S: control (glucose syrup: $60 \%$ and sucrose: $40 \%$ ). F: fructose (glucose syrup: $60 \%$ and fructose: $40 \%$ ). I:

476 isomaltulose (glucose syrup: $60 \%$ and Isomaltulose: $40 \%$ ). I30 (Isomaltulose: $30 \%$ and fructose: $70 \%$ ).

477 I50 (Isomaltulose: 50\% and fructose: 50\%). I70 (Isomaltulose: $70 \%$ and fructose: $30 \%$ ). The percentages

478 of sugars in the formulations are expressed respect the total amount of sugars in the product.

479 *Theoretical Sweetness Power (SP) of the marshmallows: $\mathrm{SP}=\sum \mathrm{m}_{\mathrm{i}} \cdot \mathrm{SP}_{\mathrm{i}} / \sum \mathrm{m}_{\mathrm{i}} \quad\left(\mathrm{m}_{\mathrm{i}}\right.$ : grams of each

480 compound; $\mathrm{SP}_{\mathrm{i}}$ : Sweetness Power of each component (individual sugar)) (González et al., 1989).

481 Similar letters indicate statistically homogenous groups.

482

483

Table 2. Mean and standard deviation of Luminosity, coordinates $a^{*}, b^{*}$, chrome and hue $(n=3)$

\begin{tabular}{ccrrrr} 
Formulation & \multicolumn{1}{c}{$\mathbf{L}^{*}$} & \multicolumn{1}{c}{$\mathbf{a}^{*}$} & \multicolumn{1}{c}{$\mathbf{b}^{*}$} & \multicolumn{1}{c}{$\mathbf{C}^{*}$} & \multicolumn{1}{c}{$\mathbf{h}^{*}$} \\
\hline S4 & $85.5(0.7)^{\mathrm{d}}$ & $10.9(1.2)^{\mathrm{bc}}$ & $1.5(0.4)^{\mathrm{c}}$ & $11.03(1.07)^{\mathrm{c}}$ & $8(3)^{\mathrm{bc}}$ \\
S5 & $86.4(0.3)^{\mathrm{ef}}$ & $10.7(0.3)^{\mathrm{bc}}$ & $2.009(0.005)^{\mathrm{d}}$ & $10.8(0.2)^{\mathrm{c}}$ & $10.6(0.3)^{\mathrm{d}}$ \\
S6 & $86.9(0.1)^{\mathrm{ef}}$ & $10.25(0.12)^{\mathrm{bc}}$ & $1.70(0.04)^{\mathrm{cd}}$ & $10.3(0.2)^{\mathrm{bc}}$ & $9.4(0.3)^{\mathrm{cd}}$ \\
\hline F4 & $82.8(0.1)^{\mathrm{b}}$ & $14.3(0.3)^{\mathrm{e}}$ & $0.4(0.4)^{\mathrm{b}}$ & $14.4(0.2)^{\mathrm{f}}$ & $1.6(1.6)^{\mathrm{a}}$ \\
$\mathbf{F 5}$ & $87.7(0.6)^{\mathrm{fg}}$ & $9.4(0.6)^{\mathrm{ab}}$ & $1.4(0.2)^{\mathrm{c}}$ & $9.5(0.6)^{\mathrm{ab}}$ & $8.9(0.8)^{\mathrm{c}}$ \\
$\mathbf{F 6}$ & $85.5(0.8)^{\mathrm{de}}$ & $11.7(0.8)^{\mathrm{c}}$ & $0.26(0.09)^{\mathrm{b}}$ & $11.7(0.8)^{\mathrm{cd}}$ & $1.2(0.4)^{\mathrm{a}}$ \\
\hline $\mathbf{I 4}$ & $81.7(0.4)^{\mathrm{a}}$ & $16.2(0.6)^{\mathrm{f}}$ & $-0.98(0.05)^{\mathrm{a}}$ & $16.2(0.6)^{\mathrm{g}}$ & $356.51(0.12)^{1}$ \\
$\mathbf{I 5}$ & $86.6(0.4)^{\mathrm{ef}}$ & $10.1(0.3)^{\mathrm{b}}$ & $2.3(0.2)^{\mathrm{e}}$ & $10.3(0.3)^{\mathrm{bc}}$ & $12.9(0.7)^{\mathrm{e}}$ \\
$\mathbf{I 6}$ & $84.2(0.9)^{\mathrm{c}}$ & $13.08(1.02)^{\mathrm{d}}$ & $0.6(0.6)^{\mathrm{b}}$ & $13.10(1.02)^{\mathrm{e}}$ & $2.8(0.7)^{\mathrm{a}}$ \\
\hline $\mathbf{I 3 0 4}$ & $84.1(0.2)^{\mathrm{c}}$ & $12.7(0.3)^{\mathrm{d}}$ & $1.52(0.13)^{\mathrm{c}}$ & $12.8(0.3)^{\mathrm{de}}$ & $6.8(0.8)^{\mathrm{b}}$ \\
$\mathbf{I 3 0 5}$ & $87.4(0.9)^{\mathrm{fg}}$ & $10.15(1.17)^{\mathrm{b}}$ & $2.1(0.2)^{\mathrm{de}}$ & $10.37(1.12)^{\mathrm{bc}}$ & $11.9(0.8)^{\mathrm{e}}$
\end{tabular}




\begin{tabular}{rrrrrr} 
I306 & $87.78(0.09)^{\mathrm{g}}$ & $9.65(0.08)^{\mathrm{ab}}$ & $2.21(0.08)^{\mathrm{de}}$ & $9.90(0.08)^{\mathrm{ab}}$ & $12.9(0.5)^{\mathrm{e}}$ \\
\hline $\mathbf{I 5 0 4}$ & $84.8(0.3)^{\mathrm{cd}}$ & $11.95(0.14)^{\mathrm{c}}$ & $1.786(0.105)^{\mathrm{d}}$ & $12.09(0.15)^{\mathrm{d}}$ & $8.5(0.4)^{\mathrm{c}}$ \\
$\mathbf{I 5 0 5}$ & $88.2(0.3)^{\mathrm{g}}$ & $9.3(0.2)^{\mathrm{ab}}$ & $1.93(0.04)^{\mathrm{d}}$ & $9.5(0.2)^{\mathrm{a}}$ & $11.7(0.3)^{\mathrm{de}}$ \\
$\mathbf{I 5 0 6}$ & $87.7(0.6)^{\mathrm{fg}}$ & $10.1(0.7)^{\mathrm{b}}$ & $1.91(0.03)^{\mathrm{d}}$ & $10.2(0.6)^{\mathrm{bc}}$ & $10.7(0.5)^{\mathrm{de}}$ \\
\hline $\mathbf{I 7 0 4}$ & $86.6(0.5)^{\mathrm{ef}}$ & $11.1(0.2)^{\mathrm{c}}$ & $1.41(0.09)^{\mathrm{c}}$ & $11.1(0.2)^{\mathrm{c}}$ & $7.2(0.5)^{\mathrm{bc}}$ \\
$\mathbf{I 7 0 5}$ & $87.33(0.05)^{\mathrm{f}}$ & $10.4(0.3)^{\mathrm{bc}}$ & $1.79(0.15)^{\mathrm{d}}$ & $10.5(0.3)^{\mathrm{bc}}$ & $9.7(0.8)^{\mathrm{cd}}$ \\
$\mathbf{I 7 0 6}$ & $88.7(0.2)^{\mathrm{g}}$ & $9.1(0.2)^{\mathrm{a}}$ & $1.93(0.09)^{\mathrm{d}}$ & $9.21(0.17)^{\mathrm{a}}$ & $12.1(0.8)^{\mathrm{de}}$ \\
\hline
\end{tabular}

484 S: control (glucose syrup: $60 \%$ and sucrose: $40 \%$ ). F: fructose (glucose syrup: $60 \%$ and fructose: $40 \%$ ). I: 485 isomaltulose (glucose syrup: 60\% and Isomaltulose: $40 \%$ ). I30 (Isomaltulose: $30 \%$ and fructose: $70 \%$ ). 486 I50 (Isomaltulose: 50\% and fructose: 50\%). I70 (Isomaltulose: 70\% and fructose: $30 \%$ ). The percentages 487 of sugars in the formulations are expressed respect the total amount of sugars in the product. The level of 488 gelatin $(4,5$ or $6 \%$ ) was subsequently noted by including the percentage of gelatine used after the code.

$489{ }^{1}$ ANOVA analysis was performed omitting this case in order to discern the statistical differences among $490 \mathrm{~h} *$ values with regard to formulations. Similar letters indicate statistically homogenous groups.

491

Table 3. F-ratio and interaction of the texture and optical parameters

\begin{tabular}{cccc}
\hline & \multicolumn{3}{c}{ Factor } \\
\cline { 2 - 4 } Variable & Formulation & \% Gelatin & Interaction \\
\hline Hardness & $262.08^{*}$ & $78.66^{*}$ & $74.07^{*}$ \\
Springiness & $17.81^{*}$ & 0.61 & $5.15^{*}$ \\
Cohesiveness & $139.82^{*}$ & $8.88^{*}$ & $21.81^{*}$ \\
Gumminess & $552.63^{*}$ & $548.23^{*}$ & $197.29^{*}$ \\
$\mathbf{L}^{*}$ & $52.14^{*}$ & $194.11^{*}$ & $12.74^{*}$ \\
$\mathbf{a}^{*}$ & $32.92^{*}$ & $119.17^{*}$ & $13.59^{*}$ \\
$\mathbf{b}^{*}$ & $95.69^{*}$ & $134.90^{*}$ & $36.00^{*}$ \\
$\mathbf{C}^{*}$ & $31.81^{*}$ & $113.91^{*}$ & $13.02^{*}$ \\
$\mathbf{h}^{*}$ & $18732.07^{*}$ & $17191.07^{*}$ & $19369.03^{*}$ \\
\hline * Statistical significance $\geq 99 \%(\mathrm{p}-\mathrm{value} \leq 0.01)$
\end{tabular}

Table 4. Pearson correlation of different attributes

\begin{tabular}{|c|c|c|c|c|c|c|c|c|c|c|c|}
\hline & $\begin{array}{l}\text { Appearan } \\
\text { ce }\end{array}$ & Colour & Aroma & Texture & Springiness & Hardness & Gumminess & Cohesiveness & Sweetness & $\begin{array}{c}\text { Global } \\
\text { preference }\end{array}$ & $\begin{array}{c}\text { Intention } \\
\text { of } \\
\text { buying }\end{array}$ \\
\hline Appearance & 1.000 & & & & & & & & & & \\
\hline Colour & $0.908^{*}$ & 1.000 & & & & & & & & & \\
\hline Aroma & 0.116 & 0.258 & 1.000 & & & & & & & & \\
\hline Texture & 0.828 & 0.617 & 0.393 & 1.000 & & & & & & & \\
\hline Springiness & 0.085 & -0.197 & 0.073 & 0.497 & 1.000 & & & & & & \\
\hline Hardness & -0.360 & -0.620 & 0.086 & 0.063 & 0.248 & 1.000 & & & & & \\
\hline Gumminess & 0.052 & -0.222 & 0.475 & 0.578 & 0.600 & 0.790 & 1.000 & & & & \\
\hline Cohesiveness & 0.268 & -0.096 & 0.184 & 0.719 & 0.845 & 0.576 & $0.878^{*}$ & 1.000 & & & \\
\hline Sweetness & 0.094 & -0.026 & 0.318 & 0.268 & -0.259 & 0.724 & 0.593 & 0.277 & 1.000 & & \\
\hline $\begin{array}{l}\text { Overall } \\
\text { preference }\end{array}$ & 0.579 & 0.210 & 0.052 & 0.832 & 0.538 & 0.497 & 0.739 & 0.871 & 0.493 & 1.000 & \\
\hline $\begin{array}{l}\text { Intention of } \\
\text { buying }\end{array}$ & 0.777 & 0.469 & 0.141 & $0.942^{*}$ & 0.486 & 0.253 & 0.617 & 0.786 & 0.389 & $0.959^{* *}$ & 1.000 \\
\hline
\end{tabular}


499 Figure 1. Values of Hardness $(\mathrm{N})$, Springiness, Cohesiveness and Gumminess $(\mathrm{N})$ of the 500 marshmallows. Codes of formulations were referred to the amount of each kind of sugar used 501 per $100 \mathrm{~g}$ of sugars in marshmallows: $\mathrm{S}$ (60 g of glucose syrup and $40 \mathrm{~g}$ of sucrose), $\mathrm{F}$ ( $60 \mathrm{~g}$ of 502 glucose syrup and $40 \mathrm{~g}$ of fructose), I (60 g of glucose syrup and $40 \mathrm{~g}$ of isomaltulose), 130 (30 $503 \mathrm{~g}$ of Isomaltulose and $70 \mathrm{~g}$ of fructose), 150 (50 g of isomaltulose and $50 \mathrm{~g}$ of fructose) and 170 504 (70 g of isomaltulose and $30 \mathrm{~g}$ of fructose). Dark grey, medium grey and light grey bars 505 correspond to 4,5 and $6 \mathrm{~g}$ of gelatine/ $100 \mathrm{~g}$ of product respectively.

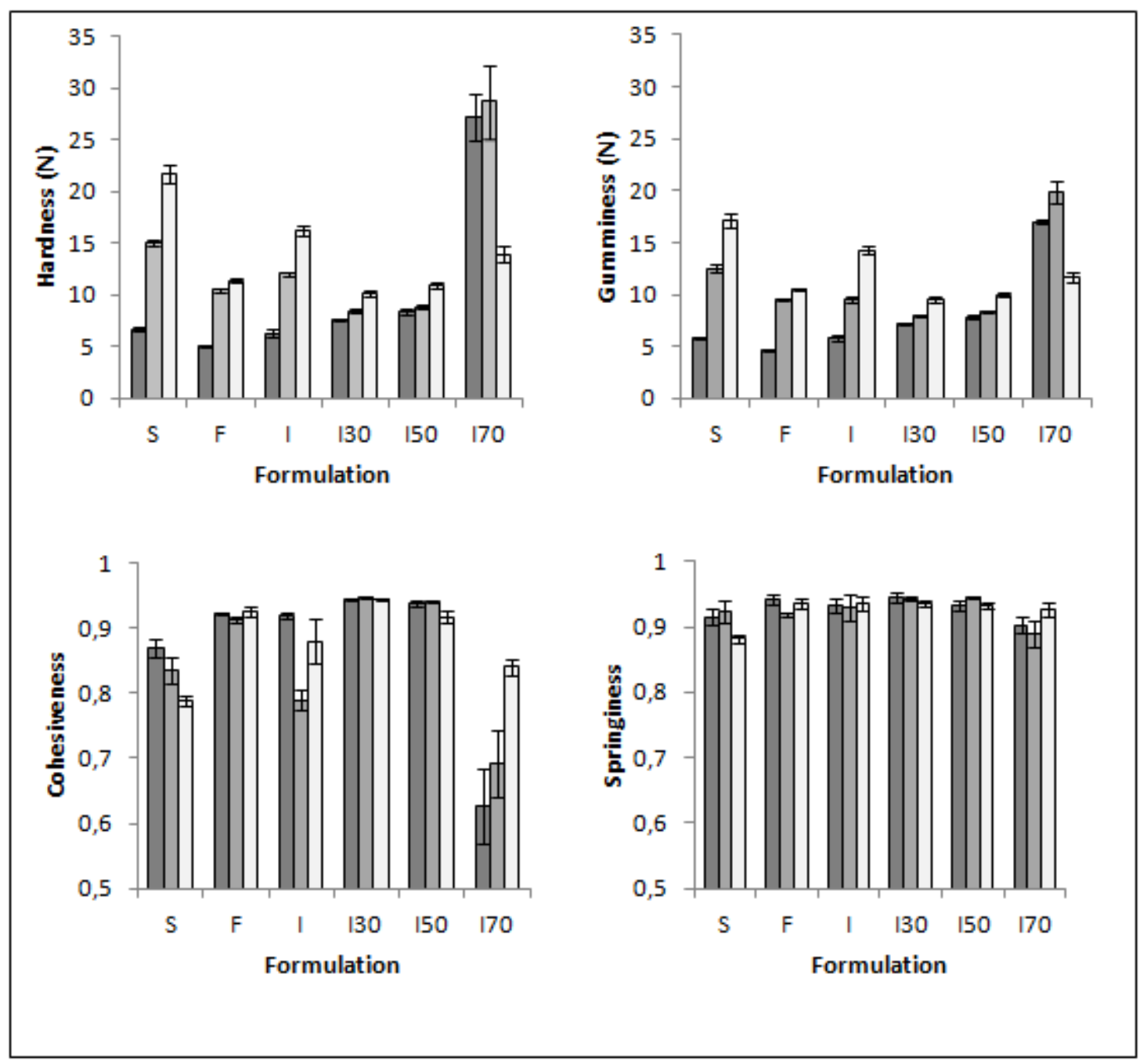

508 Figure 2. Radial chart of the average scores (1: Dislike extremely, 9: Like extremely) for each 509 attribute and the F-ratio of each attribute in brackets for the evaluated marshmallows. Dotted 510 line refers to control samples (S) formulated with $60 \mathrm{~g}$ of glucose syrup and $40 \mathrm{~g}$ of sucrose per $511100 \mathrm{~g}$ of sugars with $4 \mathrm{~g}$ of gelatine per $100 \mathrm{~g}$ of product. Dashed line refers to control samples 512 with extra aroma (S-Ar). Solid lines refer to formulation 150 which had $50 \mathrm{~g}$ of isomaltulose and $51350 \mathrm{~g}$ of fructose per $100 \mathrm{~g}$ of sugars. Black, dark grey and light grey lines indicate 4,5 and $6 \mathrm{~g}$ 514 of gelatine per 100 of product, respectively. 


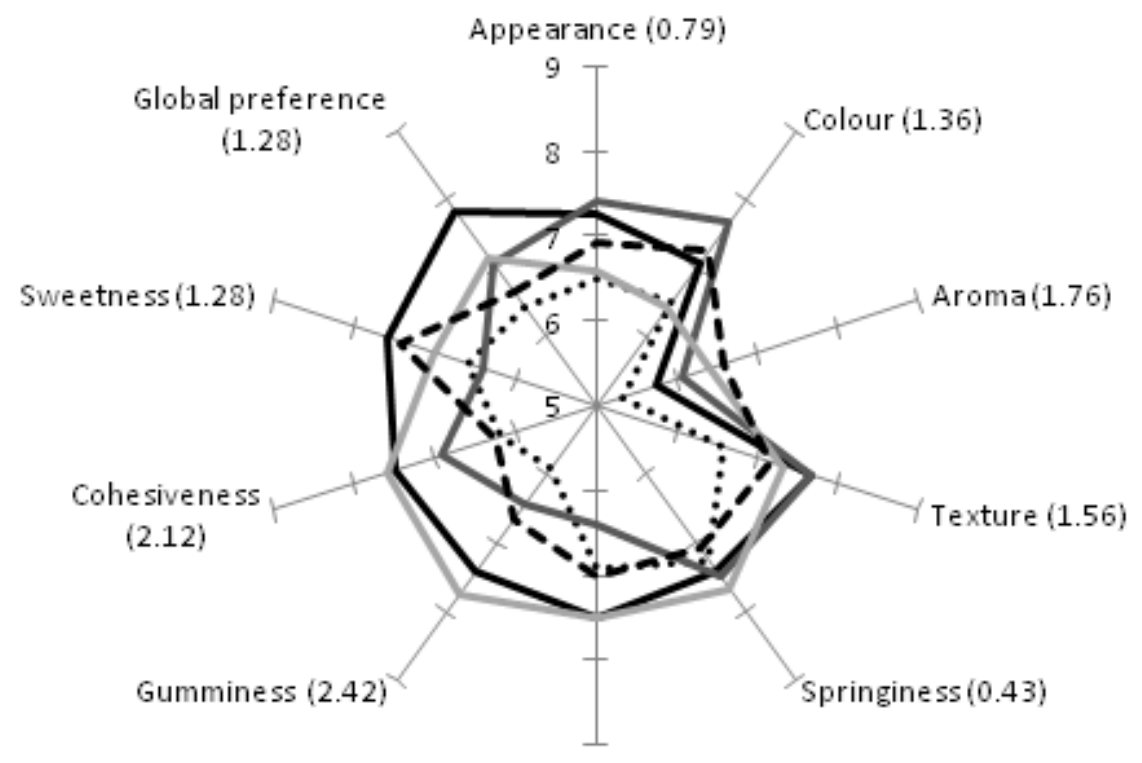

Hardness (1.45)

516 Figure 3. Bi-plot Principal Components Analysis for the samples and the attributes. Black 517 rhombus $(\diamond)$ attributes and white rhombus $(\diamond)$ samples. Codes of formulations were referred to 518 the amount of each kind of sugar used per $100 \mathrm{~g}$ of sugars in marshmallows: $\mathrm{S}$ and $\mathrm{S}-\operatorname{Ar}(60 \mathrm{~g}$ 519 of glucose syrup and $40 \mathrm{~g}$ of sucrose), and 150 (50 g of isomaltulose and $50 \mathrm{~g}$ of fructose) and $520 \quad 170(70 \mathrm{~g}$ of isomaltulose and $30 \mathrm{~g}$ of fructose). S-Ar refers to control with extra aroma. Numbers 5214,5 and 6 after the code correspond to the amount of gelatine used expressed as $\mathrm{g}$ of 522 gelatine $/ 100 \mathrm{~g}$ of product.

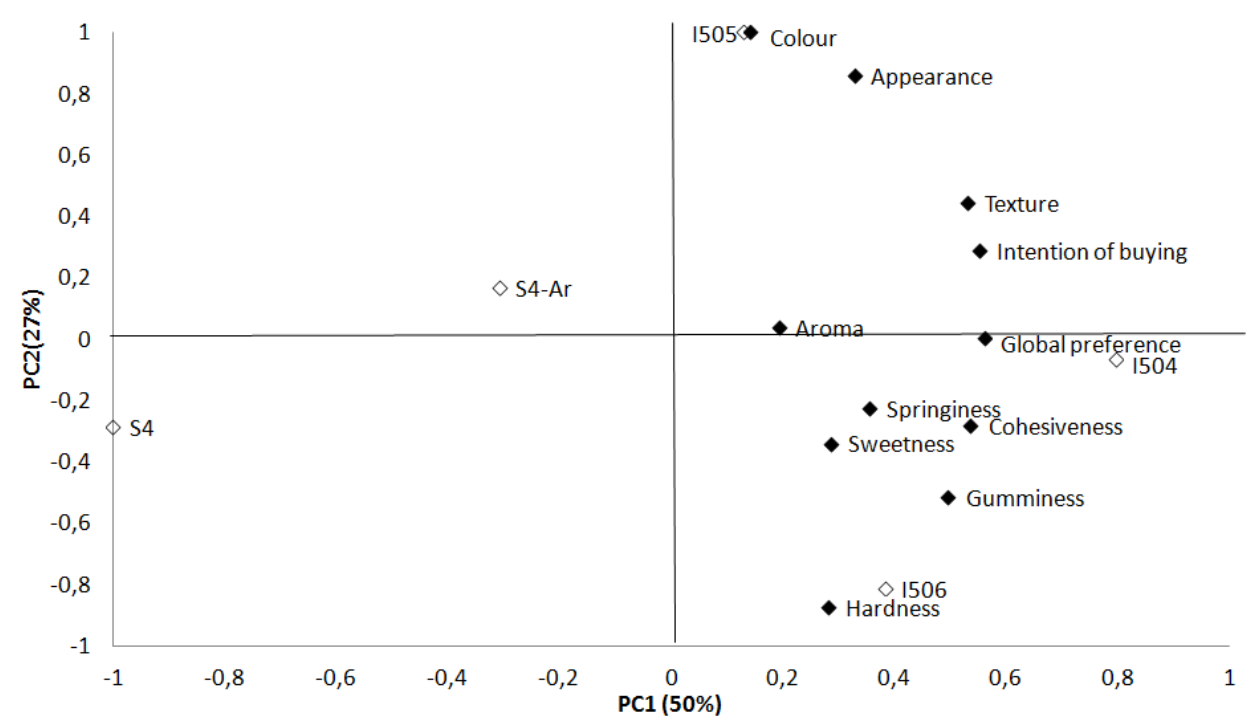


525 Figure 4. Correlation loadings $(\mathrm{X}$ and $\mathrm{Y})$ between instrumental and sensory texture variables.

526 Black rhombus ( $\bullet$ instrumental values and white rhombus $(\diamond)$ sensorial values.

527

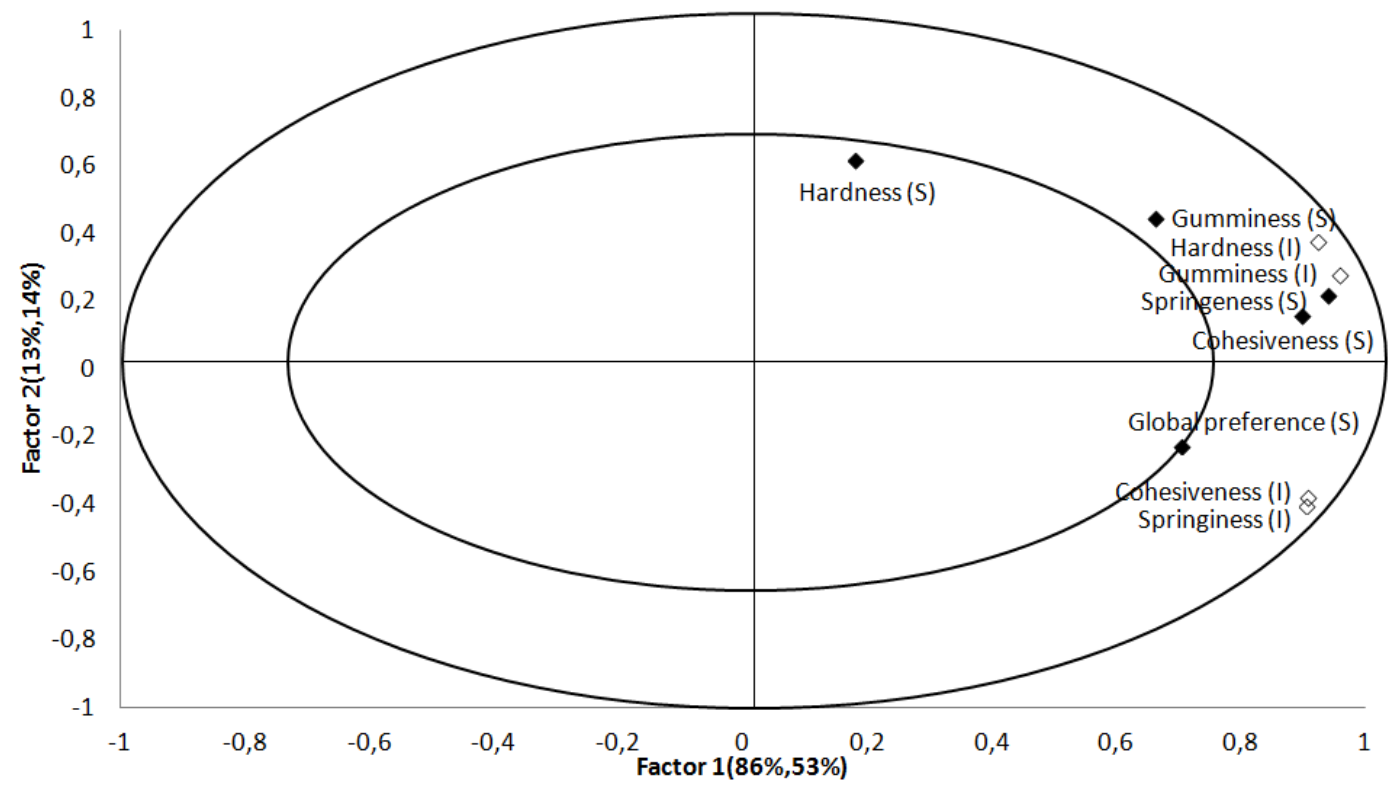

528

529 